\title{
Saúde nas fronteiras: o direito do estrangeiro ao SUS
}

Health on the boundaries: the right to SUS to foreigners

\section{Marisa Lucena Branco}

Administradora, Especialista em Direito Sanitário, em Administração pela Qualidade Total e em Gestão Hospitalar. Consultora do Ministério da Saúde. Brasília, Brasil.

Resumo: O presente artigo trata do direito do estrangeiro fronteiriço ao Sistema Único de Saúde (SUS), e em que medida ele tem esse direito. Inicialmente aborda de forma sucinta as características das fronteiras e os fluxos transfronteiras, em seguida aborda as diferentes interpretações dos operadores do direito em relação ao direito do estrangeiro ao SUS, citando dois casos que demonstra a divergência de entendimento em relação a esse direito. Ao final aborda a legislação à luz dos Direitos Humanos.

Descritores: Saúde; Sistema Único de Saúde - SUS; Fronteira; Direito.

Abstract: The present article deals with the civil rights of foreigners living in the border regions willing to access the Brazilian Health System (SUS), and on which level they entitled to this right. Initially it is presented, succinctly, the geography features of the Brazilian borders, the dynamics and the flows that take place in the border region, Further ahead, identifies differentiated interpretations of the operators of the legal right in relation to the foreigner legal right related the Brazilian Health System (SUS), having as an object of study two cases that shows the discrepancy of understanding regarding this rights. At the end, a reflection on legislation in the light of Human Rights.

Key-words: Health; Brazilian Health System (SUS); Border; Law.

\section{Introdução}

O Brasil é um país que possui onze estados que fazem fronteira com 10 países limítrofes, possuindo 588 municípios localizados na faixa de fronteira, sendo que dentre os municípios fronteiriços se verifica, embora ainda não se tenha dados quantitativos, que essas populações de países vizinhos buscam atendimento no 
sistema de saúde brasileiro (Brasil, 2008a). Para tanto, o presente artigo traz à luz a discussão em relação à diversidade de entendimento quanto ao direito do estrangeiro fronteiriço ao Sistema Único de Saúde - SUS, e em que medida ele tem esse direito.

Essa discussão tornou-se evidente com a implantação do projeto SIS Fronteiras do Ministério da Saúde entre 2005 e 2007 (Brasil, 2005c), no qual se constatou a inquietação dos Secretários Municipais de Saúde ansiosos por definições claras por parte do Ministério da Saúde quanto à conduta a ser tomada referente à demanda dos estrangeiros fronteiriços pelo SUS, bem como a preocupação dos Secretários com o ressarcimento dos gastos realizados com esses atendimentos, que em sua totalidade, são arcados somente pelos próprios municípios, sem aporte da União.

\section{Características das fronteiras e os fluxos transfronteiras}

A fronteira do Brasil possui $15.719 \mathrm{~km}$ de faixa correspondente à linha divisória com países da América do Sul, dos quais apenas o Chile e o Equador não estão dentre os países vizinhos. Detém $27 \%$ do território nacional, divididos em 588 municípios em 11 estados diferentes, que fazem fronteira com dez países limítrofes (Brasil, 2006a, p.28), a saber: Uruguai, Argentina, Paraguai, Bolívia, Peru, Colômbia, Venezuela, Guiana, Suriname, Guiana Francesa. E a faixa de fronteira do Brasil compreende uma faixa interna de até $150 \mathrm{~km}$ de largura, paralela à linha divisória terrestre do território nacional, e foi estabelecida pela Lei 6.634/79 (Brasil, 1979), uma lei foi formulada em um contexto político em que os países eram mais preocupados com suas divisões territoriais e a fronteira era considerada como espaço de Segurança Nacional, muito embora hoje se verifique um processo de mudança de paradigma. Segundo Canotilho, hoje os fins dos estados não são mais a conquista territorial, a colonização, dentre outros, mas podem e devem ser os da construção de Estados de direito democráticos, sociais e ambientais, no plano interno, e Estados abertos e internacionalmente "amigos" e "cooperadores" no plano externo (Canotilho, 2003).

A mobilidade do homem, sobretudo com a globalização, é cada vez mais comum, sendo que ao longo da fronteira esse fluxo é muito mais intenso, e sua intensidade vai depender do tipo de acesso que se tem, da infra-estrutura, e da 
proximidade entre a cidade brasileira e a estrangeira, podendo se destacar como de maior fluxo as cidades gêmeas cujo tipo de articulação seja terrestre ou fluvial com ponte. E esse fluxo transfronteira tende a ser mais comum em função da proximidade entre as cidades, porém comportamentos diferenciados, que vai depender das características de cada cidade. Uma delas é a oportunidade que oferece o Estado mais desenvolvido, em sua maioria, para a realização de tarefas pesadas, descartadas pelos profissionais qualificados desse mesmo Estado, gerando, ao longo do tempo, fluxo de trabalhadores do lado mais pobre para o mais rico do limite internacional, atraídos pelas oportunidades de trabalho e, principalmente, pelos possíveis pagamentos de assistência social no outro lado. Também ocorre a saída de trabalhadores qualificados do Estado menos desenvolvido para o mais desenvolvido, podendo se converter em potencial para grave exploração de trabalhadores ilegais na região de fronteira do mais desenvolvido. Outro elemento incentivador de fluxos transfronteira são os Serviços de consumo coletivo como saúde, educação, saneamento, dentre outros. A assimetria de oferta de serviços é responsável por fluxos transfronteiriços na maioria das cidades, com dominância de fluxos dirigidos ao Brasil. Com exceção dos casos de cidades-gêmeas com nível similar de desenvolvimento, onde é comum a duplicação desses serviços. A maior parte deles se relaciona aos serviços de saúde, que é o foco dessa pesquisa, e secundariamente a serviços de educação (Brasil, 2005a, p.155).

Pelo fato do sistema de saúde pública brasileiro ser universal, ou seja, alcança todos os municípios de fronteira e todos os cidadãos, esse fluxo é intensificado. Muitos secretários de saúde de municípios fronteiriços reclamam do fluxo constante de pessoas residente em cidades na Faixa de Fronteira do lado estrangeiro, seja de seus nacionais ou de estrangeiros, que buscam atendimento e não estão computados na base de cálculo dos recursos provenientes do SUS (Sistema Único de Saúde). Em diversas cidades-gêmeas é cada vez mais comum que os nacionais da cidade vizinha queiram ter seus filhos do lado brasileiro de forma a garantir 0 atendimento posterior, o que nem sempre é compreendido pelas prefeituras, gerando má-vontade de parte a parte (Brasil, 2005a, p.162). O acesso do fronteiriço, ou seja, do estrangeiro domiciliado em localidade contígua ao território nacional, é facilitado pela sua condição de fronteiriço, previsto na Lei no. 6.815/80 (Brasil, 1980). Essa lei prevê em seu artigo $\mathrm{n}^{\circ}$. 21, que a pessoa natural de país limítrofe domiciliado em 
cidade contígua ao território nacional pode entrar nos municípios fronteiriços ao seu país apresentando somente documento de identidade. Portanto a população fronteiriça tem seu acesso facilitado pela sua condição. O que é perfeitamente compreensível e aceitável tendo em vista a proximidade dessas cidades, além do que a própria legislação já define as condições para que esse fronteiriço possa exercer atividade remunerada ou freqüentar estabelecimento de ensino nos municípios fronteiriços. Se há previsão legal para que o fronteiriço possa exercer atividade remunerada, se os seus filhos podem freqüentar estabelecimento de ensino no Brasil, essa mesma lei poderia ter previsto o acesso aos serviços de saúde pelos mesmos motivos que levaram o legislador a incluir no texto legal estas prerrogativas ao fronteiriço. Como pode ser observado, o legislador se preocupou com o estrangeiro enquanto trabalhador, possível fonte de renda e exploração de mão de obra, mas não com a manutenção de sua saúde (Brasil, 1981).

Nas cidades-gêmeas há uma homogeneidade maior que nos demais municípios fronteiriços, há estreita ligação entre as pessoas de ambos os países, de forma a existir uma linha tênue entre esses povos, onde se verifica: brasileiros trabalhando no lado estrangeiro e morando no Brasil; brasileiros trabalhando no Brasil e residindo no lado estrangeiro; estrangeiro trabalhando no Brasil e residindo no seu país; estrangeiro residindo no Brasil e trabalhando no seu país.

\section{Os conflitos e entendimentos legais nas fronteiras}

Considerando que no Brasil não há um marco regulatório único para tratar do direito do estrangeiro ao sistema de saúde brasileiro - com exceção a acordos estabelecidos com país vizinho conforme interesses brasileiros e dependendo da relação política existente - nem normas e regras aplicáveis a todas as cidades de fronteira no que diz respeito à saúde, verifica-se que mesmo não havendo previsão há demanda da população fronteiriça por atendimento gerando conflitos, já que não há previsão legal. Verifica-se que alguns municípios atendem essa demanda dependendo do nível de complexidade, outros simplesmente se recusam a esse atendimento. A decisão acaba sendo do gestor local. O gestor passa a exercer um 
poder discricionário ${ }^{1}$ (Di Pietro, 2002), dependendo da "pressão" que ele sofre, e do seu conceito de "solidariedade", pois não há jurisprudência quanto ao direito do estrangeiro fronteiriço ao Sistema Único de Saúde, bem como aporte de recurso estadual ou federal para que o município fronteiriço atenda essa demanda. Percebe-se que a grande preocupação dos gestores é referente à capacidade financeira para atender essa demanda, uma vez que o recurso recebido é percapita $^{2}$, ou seja, por número de habitantes residentes no município, ficando, portanto, fora da contagem não só o estrangeiro fronteiriço, bem como o brasileiro residente do outro lado da fronteira.

Embora a Constituição Federal diga expressamente em seu Art.196 que a saúde é um direito de todos e dever do estado, nem todos os gestores públicos e operadores do direito têm esse mesmo entendimento, muitos divergem na interpretação da Lei. A questão é quem são esses "todos" que a Constituição quer dizer, todos os cidadãos brasileiros ou todas as pessoas que procuram o sistema de saúde? Todos os brasileiros natos e naturalizados ou também o estrangeiro? E o estrangeiro fronteiriço deve ser tratado de forma diferenciada pela sua condição de fronteiriço? E em que medida deverá ser assegurado o atendimento a esse estrangeiro fronteiriço, urgência e emergência ou também consultas eletivas? Essa diversidade de interpretação tem gerado grandes conflitos, e nem sempre esses conflitos são registrados, uma vez que o estrangeiro fronteiriço que tem seu atendimento negado não tem meios de acionar a justiça brasileira, além de gerar grandes dificuldades ao município cujo gestor de saúde decide autorizar o atendimento do estrangeiro no sistema de saúde, pois nem o Estado nem a União reconhecem esse atendimento, não repassando recursos correspondentes a essa demanda nem ressarcimento esses atendimentos.

\footnotetext{
1 Quando a Administração, diante do caso concreto, tem a possibilidade de apreciá-lo segundo critérios de oportunidade e conveniência e escolher uma dentre duas ou mais soluções, todas válidas para o direito.

2 O recurso repassado fundo a fundo pelo Ministério da Saúde para a Atenção Básica tem por base o numero de habitantes do município, conforme art. 35 da Lei 8.080 de 19 de setembro de 1990.
} 
Outro problema verificado são os requisitos para obtenção do Cartão Nacional de Saúde - Cartão SUS ${ }^{3}$, que exige o domicílio em território nacional, causando problemas de atendimento não só do estrangeiro como do brasileiro que mora do outro lado da fronteira (Brasil, 2002). A negativa de atendimento também gera grandes problemas, além da não assistência que por si já é um problema, leva o estrangeiro que necessita do atendimento a criar formas para obter acesso ao sistema de saúde brasileiro, em sua maioria meios ilegais. Muitos casos de negativa de atendimento de estrangeiros são de difícil comprovação, o que leva a inferir que casos que envolvem a tentativa de atendimento por parte de estrangeiros fronteiriços podem estar ocorrendo sem que a sociedade tenha conhecimento, com exceção aos casos de grande repercussão, como foram os casos ocorridos na cidade de Campo Grande/MS e Foz do Iguaçu/PR.

O caso ocorrido em Campo Grande foi uma constatação feita pela Promotoria Especializada de Campo Grande - Promotoria de Justiça e da Cidadania, de que um número significativo de paraguaios estavam fazendo transplante pelo SUS, encaminhados pela mesma equipe médica, cujo responsável foi apontado informalmente por um desses paraguaios como o responsável pelo aluguel de um imóvel onde os estrangeiros ficavam acomodados. As Secretarias Municipal e Estadual de Saúde instauraram processo administrativo para apurar as irregularidades que apontassem para um "agenciamento" desses estrangeiros pelo médico ou facilitação para que os mesmos fossem atendidos pelo SUS (Brasil, 2004a).

Muito embora o caso tenha ocorrido na capital, Mato Grosso do Sul é um estado que possui doze municípios fronteiriços, sendo que sete deles são considerados cidade-gêmea, que são: Corumbá, Porto Murtinho, Bela Vista, Ponta Porã, Coronel Sapucaia, Paranhos e Mundo Novo. Sendo que apenas Corumbá faz fronteira com a Bolívia, os demais municípios fazem fronteira com o Paraguai. Esses municípios servem de porta de entrada para a população do país vizinho, que por sua vez vão parar na capital em busca de atendimentos mais complexos que o município não oferece (Brasil, 2005b).

3 O Cartão Nacional de Saúde - Cartão SUS é um instrumento de identificação unívoca dos usuários do SUS e de informação sobre 0 atendimento individual prestado pelos serviços de saúde. Instituído pela Portaria/GM no. 1.560, de 29 de agosto de 2002, do Ministério da Saúde. 
Nos pontos destacados pela Promotoria de Saúde na audiência Pública que foi realizada em 05 de março de 2004, verificou-se que o entendimento é de que somente os estrangeiros residentes no Brasil fazem jus a tratamento médico pelo SUS (art. 95 da Lei 6.815), excepcionando as situações de urgência e emergência e do estrangeiro domiciliado em cidade contígua ao território nacional e atendimento na respectiva cidade limítrofe, que deve merecer tratamento específico.

Já o caso ocorrido em Foz do Iguaçu no Paraná verifica-se dois entendimentos diferentes do primeiro. Em agosto de 2006 o Ministério Público Federal, Procuradoria da República no Estado do Paraná, Procuradoria da República no Município de Foz do Iguaçu, pelo Procurador da República Alessandro José Fernandes de Oliveira, autos ํo. 2006.70.02.007108-9/PR, ajuizou na $1^{\circ}$ Vara Federal Civil de Foz do Iguaçu, Ação Civil Pública, requerendo dos três entes políticos (União, Estado do Paraná e Município de Foz do Iguaçu), fossem condenados a fornecer gratuitamente atendimento pelo SUS aos "brasiguaios" (brasileiros que residem no Paraguai), bem como a qualquer estrangeiro em Foz do Iguaçu, ainda que não residente, e mesmo que não trate de atendimento médico de urgência (Brasil, 2006b).

Tal ação se deu em decorrência da determinação do Secretário Municipal de Saúde de Foz do Iguaçu de que não fosse permitido o atendimento do estrangeiro pelo Sistema Único de Saúde - SUS, pois com a implantação do Cartão Nacional de Saúde - Cartão SUS no município o atendimento médico aos "brasiguaios" e paraguaios na estrutura do SUS ficou impossibilitado, tendo em vista os estrangeiros não preencher os requisitos para obtenção do Cartão, a saber, domicílio na base territorial do município ${ }^{4}$ (Brasil, 2002a). Chegando ao ponto, inclusive, relatado pelo próprio procurador, de uma mulher ter dado a luz a um filho no banheiro de uma unidade de atendimento por falta de atendimento, inclusive com o posterior óbito da criança (Brasil, 2006c).

A Ação teve sua sentença com Resolução de Mérito em setembro de 2008, e o juiz julgou parcialmente procedente a antecipação da tutela, determinando que

4 Art. $3^{\circ}$ O Sistema Cartão Nacional de Saúde, de validade nacional e base de vinculação territorial fundada no domicílio residencial do seu titular, é coordenado pelo Ministério da Saúde e permite o cadastramento dos usuários e profissionais de saúde e o acompanhamento contínuo dos atendimentos de saúde prestados à população (Brasil, 2002 - vigente na época). 
fosse prestado o atendimento aos brasileiros que comprovem esta qualidade, independente da apresentação do Cartão SUS ou comprovação de residência no Município, e aos que não comprovem a nacionalidade brasileira (brasiguaios/estrangeiros), somente nos casos de emergência e/ou urgência (Brasil, 2006c). Na última consulta ao site do TRF, realizada em 29 de maio de 2009, verificou-se que houve apelação por parte da Advocacia Geral da União e a lide continua em curso, mas pode ser verificado que o entendimento do procurador e dos juízes diverge quanto ao atendimento não emergencial. E na sentença não se verificou nenhum tratamento diferenciado ao estrangeiro fronteiriço.

Como pode ser observado, no caso de Campo Grande o entendimento pela Promotoria de Justiça e da Cidadania foi mais coerente para a realidade da fronteira, excepcionando o tratamento médico pelo SUS dos estrangeiros não somente nas situações de urgência e emergência, mas também do estrangeiro domiciliado em cidade contígua ao território nacional e atendimento na respectiva cidade limítrofe. Já no caso de Foz do Iguaçu verificam-se dois entendimentos, o entendimento do Procurador da República Alessandro José Fernandes de Oliveira que defende o atendimento de todo estrangeiro que se encontra em Foz do Iguaçu, enquanto que o Juiz que sentenciou a ação entende que somente nos casos de emergência e/ou urgência os estrangeiros têm direito ao SUS.

\section{Princípios e direitos: Acesso à saúde nas fronteiras}

O Título I da Constituição brasileira de 1988, composto por quatro artigos, é dedicado aos denominados "princípios fundamentais" do Estado Brasileiro. Neles se encontram os valores e os fins mais gerais e orientadores do ordenamento constitucional, funcionando como diretrizes para todos os órgãos mediante os quais atuam os poderes constituídos. O Artigo 1ำ consagra a dignidade da pessoa humana como fundamento da República Federativa do Brasil (Brasil, 1988) e define o Estado como uma organização centrada no ser humano, e não em qualquer outro referencial. A razão de ser do Estado brasileiro não se funda no próprio Estado, como ocorre nos regimes totalitários, mas sim na pessoa humana. São vários os valores constitucionais que decorrem diretamente da idéia de dignidade da pessoa humana, dentre eles, o direito à vida. $\mathrm{O}$ art.3ํㅡㄹ da Constituição Federal prevê dentre os objetivos fundamentais da República Federativa do Brasil a construção de uma 
sociedade livre, justa e solidária, bem como a promoção do bem de todos, sem preconceito de origem, raça, sexo, cor, idade, e quaisquer outras formas de discriminação, enquanto que o art. $4^{\circ}$ destaca os princípios pelo qual o Brasil é regido nas suas relações internacionais, e dentre esses princípios a prevalência dos direitos humanos e a cooperação entre os povos para o progresso da Humanidade. Já o título II trata, em cinco capítulos, dos "Direitos e Garantias Fundamentais", assegurados na Federação pelo ordenamento jurídico, destacando em seu artigo $5^{\circ}$ que todos são iguais perante a lei sem distinção de qualquer natureza, e no artigo 6o define como direitos sociais dentre outros o direito a saúde. Verifica-se, portanto, que os direitos sociais têm por objetivo a melhoria das condições de vida dos hipossuficientes, visando à concretização da igualdade social, e constituem as liberdades positivas, de observância obrigatória em um Estado Social de Direito, e no momento que os brasiguaios e os estrangeiros fronteiriços têm seu atendimento negado, estar-se-á negando vigência a própria Constituição Federal. Verifica-se ainda que os fundamentos básicos do direito à saúde no Brasil estão arrolados nos artigos 196 a 200, em atendimento às garantias, princípios e fundamentos constitucionais já mencionados, onde prevê expressamente o direito de todos à saúde e o dever do Estado de prestá-la por meio do Sistema Único de Saúde, que tem como uma de suas diretrizes básicas o atendimento integral à saúde:

O direito à saúde, tal como assegurado na Constituição de 1988, configura direito fundamental de segunda geração, abrangendo os direitos sociais, culturais e econômicos que se caracterizam por exigirem prestações positivas do Estado. Os direitos de segunda geração conferem ao indivíduo o direito de exigir do Estado prestações sociais (positivas) nos campos da saúde, alimentação, educação, habitação, trabalho, dentre outros. Com fundamento de validade nestes dispositivos constitucionais, o legislador ordinário editou a Lei no. 8.080 de 19 de setembro de 1990, que cria o SUS - Sistema Único de Saúde e afirma categoricamente em seu artigo $2^{\circ}$ que a saúde é um direito fundamental do ser humano, devendo o Estado prover as condições indispensáveis ao seu pleno exercício (Brasil, 1990). Verificase ainda em seu artigo №. 35 a previsão de combinações de critérios para o estabelecimento de valores a serem transferidos a Estados, Distrito Federal e Municípios, como o perfil demográfico da região, o perfil epidemiológico da população a ser coberta, e estabelece no $\S 2^{\circ}$ que nos casos de Estados e Municípios sujeitos a notório processo de migração os critérios demográficos 
mencionados na respectiva Lei serão ponderados por outros indicadores de crescimento populacional. Portanto, a lei já prevê a situação de migração, restando portanto a criação de mecanismos para mensurar esse fluxo migratório. E verificase que o próprio Cartão SUS deveria identificar esses fluxos migratórios, e não ser utilizado como instrumento de limitação de acesso aos estrangeiros ou brasileiros residentes fora dos limites territoriais.

Além de todos os aspectos constitucionais apresentados, verificam-se outros dispositivos que corrobora com o entendimento de que o estrangeiro é alcançado pelas garantias constitucionais. O Decreto no. 18.956/29 promulgou seis convenções de Direito Internacional Público, aprovada pela Sexta Conferência Internacional Americana, dentre elas a Convenção sobre os Estrangeiros, do qual o Brasil é signatário. Essa convenção estabelece em seu artigo n‥ 5 que os Estados devem conceder aos estrangeiros domiciliados ou de passagem em seu território todas as garantias individuais que concedem aos seus próprios nacionais e o gozo dos direitos civis essenciais:

Art. 5․ Os Estados devem conceder aos estrangeiros domiciliados ou de passagem em seu território todas as garantias individuais que concedem nos seus próprios nacionais e o gozo dos direitos civis essenciais, sem prejuízo, no que concerne aos estrangeiros, das prescrições legais relativas á extensão e modalidades do exercício dos ditos direitos e garantias (Brasil, 1929).

Analisando os argumentos apontados até o momento, as características das fronteiras brasileiras, os fluxos, a integração e as relações existentes nesse território como foi citado nos Diagnósticos Locais de Barra do Quarai e Sant'Santana do Livramento no Rio Grande do Sul, observa-se que a integração é um fato que já ocorre, com ou sem amparo legal. É um movimento em crescente evolução, e o Brasil não é apenas "explorado" em seu sistema de saúde como apontado no caso de Foz do Iguaçu, mas em outras situações ocorrem trocas e se estabelece um território diferenciado nessas regiões.

O direito à saúde é uma garantia indissociável do direito à vida, a negação do atendimento a esses estrangeiros fere não apenas os princípios constitucionais como também os tratados firmados pelo Brasil, entre eles o Pacto de San José da Costa Rica, que é a Convenção Americana sobre Direitos Humanos, do qual o Brasil é signatário, e estabelece em seu art.4º, item 1: "Toda pessoa tem o direito de que se respeite sua vida. Esse direito deve ser protegido pela lei e, em geral, desde 
o momento da concepção." E em seu art.5”, item 1: "Toda pessoa tem direito a que se respeite sua integridade física, psíquica e moral” (Brasil, 1969).

A Declaração Universal dos Direitos do Homem - um dos documentos básicos das Nações Unidas, assinado em 1948 - também estabelece em seu Artigo III o direito à vida: "Todo ser humano tem direito à vida, à liberdade e à segurança pessoal". Muito embora não seja um tratado, por isso seus dispositivos não constituem exatamente uma obrigação jurídica para cada um dos Estados representados na Assembléia Geral quando se adotou respectivo texto sob a forma de uma resolução da Assembléia (Rezek, 1991).

Somando-se aos argumentos já apresentados, vale destacar a contribuição do constitucionalista J.J. Gomes Canotilho a respeito de um novo paradigma. Canotilho defende as sugestões do "paradigma emergente" que alguns designam como constitucionalismo global. Os traços caracterizadores deste novo paradigma emergente são: alicerçamento do sistema jurídico-político internacional centrado nas relações entre Estado/povo, ou seja, as populações dos próprios estados, e não mais relações horizontais entre estados; emergência de um jus cogens internacional materialmente informado por valores, princípios e regras universais progressivamente plasmados em declarações e documentos internacionais e; tendêncial elevação da dignidade humana e pressupostos ineliminável de todos os constitucionalismos (Canotilho, 2003).

Dos diversos tratados firmados, à luz do conteúdo da Declaração dos Direitos do Homem de 1948 e da realidade encontrada nas fronteiras do Brasil, verifica-se que a mudança para este modelo caminha lentamente, considerando que os países ainda se assentam no constitucionalismo nacional nas relações internacionais no que se refere à saúde. Diferentemente dos setores econômicos em que avança a globalização e transnacionalização. No entendimento de Canotilho, estes parâmetros teóricos influenciam hoje claramente as imbricações do direito constitucional com o direito internacional. As relações internacionais devem ser cada vez mais relações reguladas em termos de direito e justiça convertendo o direito internacional numa ordem imperativa.

[...] o direito internacional tende a transformar-se em suporte das relações internacionais através da progressiva elevação dos direitos humanos - na parte em que não integrem já o jus cogens - o padrão jurídico de conduta política, interna e externa. Estas últimas premissas - o jus cogens e os direitos humanos -, articuladas 
com o papel da organização internacional, fornecerão um enquadramento razoável para o constitucionalismo global (Canotilho, 2003).

\section{Comentários finais}

Em analise à legislação e aos argumentos apresentados verifica-se que o estrangeiro fronteiriço tem direito a tratamento diferenciado mas nem sempre de fato. Verifica-se ainda que muito embora a Lei $\mathrm{n}^{\circ}$. 8.080/90 preveja 0 estabelecimento de outros critérios para fixação de valores que são transferidos a Estados e Municípios sujeitos a notório processo de migração, a prática ainda é pelo seu número populacional, o que prejudica sobremaneira os municípios fronteiriços. A falta de definição por parte do Ministério da Saúde deixa a critério e ao entendimento e juízo de valor de cada gestor. Outro aspecto verificado é que o Cartão SUS não está sendo utilizado em sua plenitude, mas por alguns municípios, como foi o caso de Foz do Iguaçu/PR, foi utilizado como forma de restrição de direitos. Sendo que, mesmo que o estrangeiro fronteiriço não tenha direito ao Cartão SUS, só o seu cadastramento no ato do atendimento poderia mensurar a demanda, identificando o fluxo migratório, equacionando as questões de saúde bem como a capacidade de custeio e a sustentabilidade financeira dos municípios fronteiriços, fazendo valer o $\S 2^{\circ}$ do artigo 35 da Lei $n \div$. 8.080/90, que estabelece que os municípios sujeitos a notório processo de migração, os critério demográficos estabelecidos para transferência de recursos serão ponderados por outros indicadores.

Reconhecer esse direito nada mais é do que dar legitimidade ao que já acontece nas fronteiras. E como conseqüência desse reconhecimento, deverá ser identificada às ações que atualmente são intercambiadas e a elas conferir legitimidade jurídica (Gallo, 2004). Além disso, é fundamental a definição clara desse entendimento de forma a subsidiar as ações hoje em curso.

Uma vez reconhecendo o fluxo hoje existente, será possível mensurar o volume de atendimento, que até então não foi identificado, podendo servir de subsídios para as questões diplomáticas e para novos acordos que poderá conter compensações financeiras ou trocas de serviços. Como bem escreveu Fernando Aith em sua reflexão sobre a definição do Direito de L. Assier-Andreu:

O Direito é uma realidade social, um composto de atividades humanas marcado, como todas as atividades humanas, pela cultura e pelas formas de 
organização de cada sociedade. Ela é uma realidade singular. Ela é ao mesmo tempo o reflexo de uma sociedade e o projeto de agir sobre ela; a base da organização social e um meio para canalizar o desenrolar das relações entre indivíduos e grupos... [...]. Se o Direito é uma realidade social, é também uma teoria ativa da sociedade, uma avaliação do que existe com o objetivo de determinar o que deveria existir (Aith, 2007).

\section{Rererências}

AITH, Fernando. Curso de Direito Sanitário: a proteção do direito à saúde no Brasil. São Paulo: Quartier Latin, 2007. ISBN: 85-7674-262-4.

BONAVIDES, Paulo. Curso de Direito Constitucional. 23 ed. São Paulo : Malheiros, 2007. ISBN: 85.7420-886-8.

BRANCO, Marisa Lucena. O SUS na fronteira e o direito: Em que medida o estrangeiro tem direito ao SUS. 2009. (Monografia) Especialização em Direito Sanitário; Fundação Oswaldo Cruz, Brasília, 2009.

BRASIL. Constituição da República Federativa do Brasil, de 5 de outubro de 1988. Disponível em: <http://www.planalto.gov.br>. Acesso em: 05 set. 2009.

BRASIL. Decreto no. 18.956, de 22 de outubro de 1929. Promulga seis convenções de Direito Internacional Público, aprovadas pela Sexta Conferência Internacional Americana. Disponível em: <http://www2.mre.gov.br/dai/estrangeiros. htm>. Acesso em: 20 set. 2009.

BRASIL. Decreto n. 86.715, de 10 de dezembro de 1981. Regulamenta a Lei n․ 6.817, de 19 de agosto de 1980. Define a situação jurídica do estrangeiro no Brasil, e cria o Conselho Nacional de Imigração e da outras providências. Disponível em: <http://www2.mre.gov.br/dai/estrangeiros.htm>. Acesso em: 20 set. 2009.

BRASIL. Instituto Brasileiro de Geografia e Estatística (IBGE). Estimativas das populações residentes em $1^{\circ}$ de julho de 2008, segundo os municípios. 2008a. Disponível em: <http://www.ibge.gov.br/home/estatistica/populacao/estimativa2008/POP2008_ DOU.pdf>. Dados de 2008a. Acesso em: 05 de jul. 2009.

BRASIL. Lei no. 6.634, de 2 de maio de 1979. Dispõe sobre a Faixa de Fronteira, altera o Decreto-lei nº. 1.135, de dezembro de 1970, e dá outras providências. Disponível em: <http:www.planalto.gov.br/ccivil_03/Leis/L6634.htm>. Acesso em: 10 jul. 2009.

BRASIL. Lei no. 6.815, de 19 de agosto de 1980. Define a situação jurídica do estrangeiro no Brasil, cria o Conselho Nacional de Imigração. Disponível em: <http:www.planalto.gov.br/ccivil_03/Leis/L6815.htm>. Acesso em: 06 ago. 2009.

BRASIL. Lei n․ 8.080, de 19 de setembro de 1990. Dispõe sobre as condições para a promoção, proteção e recuperação da saúde, a organização e o funcionamento dos serviços correspondentes e dá outras providências. 
Disponível em: <http://www.planalto.gov.br/ccivil_03/Leis/L8080.htm>. Acesso em: 06 jul. 2009.

BRASIL. Ministério da Integração Nacional. Secretaria de Programas Regionais. Proposta de Reestruturação do Programa da Faixa de Fronteira. Brasília : Ministério da Integração Nacional, 2005a.

BRASIL. Ministério da Saúde. Sistema Integrado de Saúde das Fronteiras. Projeto SIS Fronteiras, Instituído em 2005b. Disponível em <http://www.saude.gov.br/sisfronteiras>. Acesso em: 03 jun. 2009.

BRASIL. Ministério da Saúde. Processo no. 25000.137111/2006-03. Solicita subsídios para defesa da união no processo no 200670020071089 que requer 0 fornecimentos de medicamentos para os brasiguaios. Brasília: Ministério da Saúde, 2006c.

BRASIL. Ministério da Saúde. Secretaria Executiva. Direito dos usuários dos serviços e das ações de saúde no Brasil: Legislação federal compilada - 1973 a 2006. Brasília: Editora do Ministério da Saúde, 2007.

BRASIL. Ministério das Relações Exteriores. Organização dos Estados Americanos. Convenção Americana sobre Direitos Humanos. 22/11/1969. Disponível em <http://www2.mre.gov.br/dai/m_678_1992.htm>. Acesso em: 13 jun. 2009.

BRASIL. Ministério Público do Estado de Mato Grosso do Sul. Promotoria de Justiça da Cidadania (PROCID). Ata de Reunião realizada no dia 05.03.2004 referente a transplante de doadores e receptores vivos, 2004a.

BRASIL. Ministério Público Federal. Ação Civil Pública no. 2006.70.02.007102$9 / P R$, de 2006b. Disponível em: http://www.trf4.jus.br/trf4/processos/visualizar_documento _gedpro.php?local.Acesso em: 01 jun. 2009.

BRASIL. Portaria GM/MS no 940, de 28 de abril de 2011. Regulamenta 0 Sistema Cartão Nacional de Saúde (Sistema Cartão). Disponível em: <http://www.brasilsus.com.br/legislacoes/gm/107959-940.html>. Acesso em: 27 jun. 2011.

BRASIL. Portaria GM/MS no. 1.560, de 29 de agosto de 2002. Institui o Cartão Nacional de Saúde - Cartão SUS e da outras providências. Disponível em: <http://bvsms.saude.govbr/bvs/saudelegis/gm/2002/prt1560_29_08_2002.html> . Acesso em: 20 jun. 2009.

BRASIL. Portaria GM/MS no. 1.120, de 6 de julho de 2005c. Institui o Sistema Integrado de Saúde das Fronteiras - SIS Fronteiras. Disponível em: http://portal.saude.gov.br/portal/saude/profissional/visualizar_texto.cfm?idtxt=23 980>. Acesso em: 15 mai. 2009.

BRASIL. Portaria GM/MS no 2.048, de 3 de setembro de 2009. Aprova o Regulamento do Sistema Único de Saúde (SUS). Disponível em: <http://portal.saude.gov.br/portal/arquivos/pdf/regulamento_sus_240909.pdf>. Acesso em: 27 jun. 2011.

CANOTILHO, Joaquim Gomes Canotilho. Direito Constitucional e Teoria da Constituição. 7 ed. Portugal: Coimbra, 2003. ISBN: 978-972-40-2106-5. 
COSTA, Laís (Org.). Integração de Fronteiras: Possibilidades Brasil-Bolívia na Saúde. Brasília: Ministério da Saúde, Ministério da Integração Nacional, Organização Pan-Americana da Saúde, 2006. ISBN: 85-87943-54-5.

DI PIETRO, Maria Sylvia Zanella. Direito Administrativo. 14 ed. São Paulo: Atlas, 2002. ISBN: 85-224-3118-3.

GALLO, Edmundo. Sistema Integrado de Saúde do MERCOSUL: SIS MERCOSUL: uma agenda para integração. In: GALLO, Edmundo; COSTA, Laís (Org). A Integração dos Sistemas de Saúde que atendem a população fronteiriça dos países do MERCOSUL - SIS - MERCOSUL. Brasília: OPAS, 2004. ISBN: 85-87943-35-9.

MAXIMILIANO, Carlos. Hermenêutica e aplicação do Direto. (monografia). Rio de Janeiro: Forense, 1994.

MELLO, Celso D. de Albuquerque. Direito Internacional Público: Tratados e Convenções. 5 ed. São Paulo: Renovar, 1997. ISBN: 85-7147-044-8.

MORAES, Alexandre de. Direito constitucional. 8. ed. São Paulo: Atlas, 2000. ISBN: 85-224-2659-7.

OEA - Organização dos Estados Americanos. Convenção Americana sobre Direitos Humanos. 1969. Disponível em < http://www2.mre.gov.br/dai/m_678_1992.htm >. Acesso em: 13 jun. 2009.

OEA - Organização dos Estados Americanos. Protocolo Adicional à Convenção Americana sobre Direitos Humanos em matéria de Direitos Econômicos, Sociais e Culturais: Protocolo de San Salvador. 1988. Disponível em:

<http://www.cidh.org/Basicos/Portugues/e.Protocolo_de_San_Salvador.htm>. Acesso em 11 set. 2008.

PAULO, Vicente; ALEXANDRINO, Marcelo. Direito Constitucional Descomplicado. 3. ed. Rio de Janeiro: Forense; São Paulo: Método, 2008. ISBN: 978-85-309-2794-3.

TORRONTEGUY, Marco Aurélio Antas. O direito humano à saúde no direito internacional: efetivação por meio da cooperação sanitária. (Tese de Doutorado) São Paulo: Universidade de São Paulo, 2010. Disponível em: <http://www.teses.usp.br/teses/disponiveis/2/2140/tde-14032011-154326>.

Acesso em: 23 mar. 2011.

REZEK, José Francisco. Direito internacional público: curso elementar. (monografia) 2 ed. São Paulo: Saraiva, 1991. 